\title{
Personalized Pricing and Quality Differentiation
}

\author{
Vidyanand Choudhary \\ Paul Merage School of Business, University of California, Irvine, California 92697, \\ veecee@uci.edu \\ Anindya Ghose \\ IOMS/IS Group, Leonard N. Stern School of Business, New York University, Henry Kaufman Management Center, \\ 44 West 4th Street, New York, New York 10012, aghose@stern.nyu.edu \\ Tridas Mukhopadhyay \\ Tepper School of Business, Carnegie Mellon University, Pittsburgh, Pennsylvania 15213, \\ tridas@andrew.cmu.edu \\ Uday Rajan \\ Stephen Ross School of Business, University of Michigan, 701 Tappan Street, Ann Arbor, Michigan 48109, \\ urajan@bus.umich.edu
}

\begin{abstract}
$\mathrm{W}^{\mathrm{e}}$ e develop an analytical framework to investigate the competitive implications of personalized pricing (PP), whereby firms charge different prices to different consumers based on their willingness to pay. We embed PP in a model of vertical product differentiation and show how it affects firms' choices over quality. We show that firms' optimal pricing strategies with PP may be nonmonotonic in consumer valuations. When the PP firm has high quality, both firms raise their qualities relative to the uniform pricing case. Conversely, when the PP firm has low quality, both firms lower their qualities. Although many firms are trying to implement such pricing policies, we find that a higher-quality firm can actually be worse off with PP. While it is optimal for the firm adopting PP to increase product differentiation, the non-PP firm seeks to reduce differentiation by moving in closer in the quality space. While PP results in a wider market coverage, it also leads to aggravated price competition between firms. Because this entails a change in equilibrium qualities, the nature of the cost function determines whether firms gain or lose by implementing such PP policies. Despite the threat of first-degree price discrimination, we find that PP with competing firms can lead to an overall increase in consumer welfare.
\end{abstract}

Key words: personalized pricing; quality differentiation; price competition

History: Accepted by Jagmohan S. Raju, marketing; received February 3, 2003. This paper was with the authors $8 \frac{1}{2}$ months for 3 revisions.

\section{Introduction}

Different consumers typically derive different value from the same product. Firms often respond to this heterogeneity in valuations by trying to determine what customers will pay. This is done in a variety of ways: by understanding the nature of a customer's business and how the product will be used, by asking about their budget during a negotiation, or via market research using different collaborative and content-filtering techniques. The information about willingness to pay is then used to provide a personalized price for the customer.

In this paper, we use the term personalized pricing, or PP, to refer to the limiting case in which a firm can implement a pricing policy based on complete knowledge of the willingness to pay of each consumer. ${ }^{1}$

\footnotetext{
${ }^{1}$ Because the amount of information required for implementing $\mathrm{PP}$ is high, in practice, firms may not know valuations precisely. Hence, our results should be interpreted as the solution to an important limiting case that provides a useful benchmark-the case of perfect information.
}

We bypass the question of how the firm acquires this knowledge. Rather, we focus on the implications this has for firm strategies. Specifically, we examine the following questions: (i) How does competition affect equilibrium product quality outcomes when firms engage in PP? (ii) Does the improvement in firms' knowledge of individual consumers alleviate or intensify price competition? (iii) What are the trade-offs firms face in adopting PP? (iv) How does PP affect consumer welfare?

Examples of PP come from the markets for both consumer and business products. Firms selling large proprietary enterprise-level software often finalize the price through a negotiation. Vendors typically work with clients to conduct a return on investment (ROI) analysis to determine the benefit (in the form of cost savings or revenue enhancements) of the product to the client. Sweeney et al. (2002) describe such a collaborative development of ROI by Teradata Inc. in fostering sales of its data-warehousing technology. The ROI analysis is used to price software. For instance, 
a California-based in-store demand-planning software developer sets the price as a percentage of a mutually determined ROI. This is also common practice in the sale of enterprise telephone cost auditing software. ${ }^{2}$

The market for computer servers, storage devices, and workstations in the Asia-Pacific region combines PP and quality differentiation. Major players such as IBM, Hewlett Packard, and Sun Microsystems use personalized discounting for different customers based on ROI, even at the same quality levels. There is also a trend towards increasing the degree of service quality and value-added software differentiation in the industry. For instance, in the UNIX platform, HP and IBM cater to the high-end market, while Sun serves the low-end market (TechWise Research, Inc. 1999). Other examples of value-based PP are found in the healthcare (Smith and Nagle 2002) and chemicals industries.

Online retailers with their ability to collect data are well positioned to take advantage of dynamic pricing. In a well-known example, Amazon offered different prices to different consumers on its popular DVD titles (Morneau 2000). Although Amazon's experiment was short-lived due to a consumer backlash, it has since found innovative ways of implementing PP without annoying consumers, through the use of the "Gold Box." Each consumer is provided access to a prominently displayed Gold Box with their name (e.g., John Doe's Gold Box) on web pages at Amazon. Opening the Gold Box provides access to a limited number of products with special discounts that are not available outside the Gold Box. The items offered in the Gold Box are different for different consumers. This allows Amazon to charge personalized prices. This is an example of the continuing evolution of PP and an indication of the likely use of such pricing by online retailers. Chen and Iyer (2002) mention several other examples of customized pricing, ${ }^{3}$ and Wertenbroch and Skiera (2002) provide an empirical study that compares several approaches for determining consumer willingness to pay.

We consider a vertically differentiated duopoly framework in which one or both firms can perfectly identify valuations of heterogenous consumers. ${ }^{4}$

\footnotetext{
${ }^{2}$ These anecdotes were communicated to us in conversations with Steve Acterman, Director Corporate IT Management, Volt Information Sciences; Harnish Kanani, Senior Vice President Global Services, Emagia Corporation; and Tim Johnson, Account Executive, Apreo Inc.

${ }^{3}$ These include major providers of long-distance telephone service (such as AT\&T, MCI, and Sprint), direct marketing companies like Land's End and L. L. Bean, who have individual specific catalog prices, and financial services and banks, who engage in PP through personalized discounts on card fees. Zhang (2003) mentions Wells Fargo and MBNA in this regard.

${ }^{4}$ We ignore the possibility of mistargeting. Chen et al. (2001) show that mistargeting can have an important effect by softening price
}

A monopolist with such information could engage in first-degree price discrimination. As Armstrong and Vickers (2001) point out, the literature on competitive price discrimination is not as extensive as in the monopoly case. They provide an elegant framework that incorporates much of the earlier work on price competition in an environment with multiple firms. Recent work on customer recognition and behaviorbased price discrimination includes Villas-Boas (1999) and Acquisti and Varian (2005). Much of the recent work on perfect price discrimination has been done either in the context of horizontal product differentiation (Thisse and Vives 1988, Chen and Iyer 2002, Ulph and Vulkan 2002, Bhaskar and To 2004) or monopoly (Aron et al. 2005). Shaffer and Zhang (2002) consider perfect price discrimination by competing firms in a model that includes both horizontal and vertical differentiation. Desai (2001) analyzes second-degree price discrimination with both vertical and horizontal differentiation. Dellaert and Syam (2002) bring into focus the issues surrounding mass customization via an analysis of consumer-producer interaction. We contribute to the literature in this field by incorporating perfect price discrimination in a vertically differentiated duopolistic setting. Because our paper examines the issue of how firms' knowledge of individual customers affects the nature of their strategic interactions, it complements the work done on how customers' knowledge about firms may affect firms' competitive strategies (Lal and Sarvary 1999 and Zettelmeyer 2000).

We derive a number of analytical results on firm pricing, quality differentiation, and consumer welfare when one or both firms have PP. First, if the firm with PP has low quality, its optimal price is nonmonotonic in consumers' willingness to pay. That is, some highvaluation consumers are offered lower prices than some low-valuation ones. Second, when one firm adopts PP, the other firm responds by lowering its price. This is a competitive response: A firm with PP knows the valuation of each consumer, and can therefore charge prices as low as its own marginal cost to a specific consumer. It therefore encroaches into the market share of the other firm, which responds to the increased competition by reducing its price. Third, when only one of the firms adopts PP, it is optimal for it to increase product differentiation. This can be interpreted as a move to reduce competition with the other firm. When the cost of quality is quadratic, if the low-quality firm adopts PP, both firms reduce their quality levels. Conversely, when the high-quality firm adopts PP, both firms increase their quality levels. We show that when

competition in the market and qualitatively changing the incentives for competing firms engaged in individual marketing. 
both firms adopt PP, the high-quality firm reduces its quality, while the low-quality firm raises its quality. Finally, consumer surplus falls (compared to the no PP case) if the PP firm has low quality, but rises if the PP firm has high quality. In fact, consumer surplus is highest when both firms have PP.

In addition to the above results, for a wide range of cost parameters, we demonstrate some properties of firm profit with PP. First, within this range, it is a dominant strategy for the low-quality firm to adopt PP. That is, regardless of whether the high-quality firm adopts PP or not, the low-quality firm makes a higher profit with PP. Conversely, the high-quality firm can actually be worse off with PP, and should adopt PP only if the costs of quality are not too steep. This paradox emerges because in a vertical differentiation context, the other firm responds by lowering its quality. Next, if marginal costs sharply increase in quality, then both firms earn lower profits compared to the case where neither has PP. Essentially, they are trapped in a prisoner's dilemma. ${ }^{5}$ However, if costs are not too convex, both firms increase profits when they adopt PP. Thus, our paper highlights that the cost-of-quality effect can lead to circumstances wherein firms can avoid the prisoner's dilemma situation when they both have PP.

The rest of this paper is organized as follows. Section 2 briefly describes the model. In $\S 3$, we show that when only one firm has PP, there are two possible equilibria, with the PP firm having either a low quality or a high quality. ${ }^{6}$ We next consider the case of both firms using PP. In $\S 4$, we analyze the impact of PP on firms' profits and consumer surplus. This allows us to consider the question of when firms will adopt PP. We discuss some implications of our findings in $\$ 5$. All proofs are relegated to the online appendix (at http://mansci.pubs.informs.org/ ecompanion.html).

\section{Model}

We consider PP in a duopoly model of vertical differentiation. ${ }^{7}$ Two firms compete in both the quality and price of the products they offer. Formally, we model their competition as a three-stage game. At the first stage, firms simultaneously choose the quality levels

\footnotetext{
${ }^{5}$ Thisse and Vives (1988) obtain similar results in models of price discrimination.

${ }^{6}$ We do not consider the question of which equilibrium will emerge. In our model, neither firm has the option of forcing the other into a particular equilibrium.

${ }^{7}$ Shaked and Sutton (1982) and Gabszewicz and Thisse (1986), building on research by Mussa and Rosen (1978), develop duopoly models of vertical differentiation and show that to reduce price competition, firms seek maximal product differentiation. Moorthy (1988) extends the basic model by incorporating variable production costs and allowing consumers the opportunity to not buy a product. This results in less than maximal product differentiation.
}

of their products. At Stage 2, the firms choose their prices. When neither firm has access to PP, prices are chosen simultaneously. When only one firm has access to PP, the firm without PP chooses its price first, followed by the firm with access to PP. PP is executed for each consumer at the point of sale. Hence, a firm that engages in PP chooses its price after a rival that has a uniform pricing policy (which must be posted and committed to before sales occur). In other words, the flexibility implied by PP incorporates an implicit assumption on flexibility in timing as well. When both firms have PP, the order of moves at Stage 2 does not affect the outcome; for convenience, we again posit that prices are chosen simultaneously. Once prices are chosen, at the last stage of the game (Stage 3), consumers decide which, if any, product to buy.

If a consumer purchases a product of quality $q$ at price $p$, his utility is $U(\theta)=\theta q-p$, where $\theta \in[0,1]$. A consumer has positive utility for one unit only. The type parameter $\theta$ indicates a consumer's marginal valuation for quality. For any given quality, a consumer with a higher $\theta$ is willing to pay more for the product than one with a lower $\theta$. If either of the two products offers a positive net utility, a consumer buys the one that maximizes his surplus. Otherwise, he chooses not to buy either product. It is immediate to show in this model that, if the qualities of the firms are the same, PP adds no value - the result is Bertrand competition, with both firms pricing at marginal cost. Hence, in this paper, we consider a model in which firms first choose qualities (which will be different in equilibrium), and then prices.

Consistent with prior literature, we assume that firms have a marginal cost of production that is invariant with the quantity, but depends on the quality, of the product. That is, both firms have the same cost function, but depending on the quality levels they choose, their marginal costs may differ in equilibrium. Each firm has a constant marginal cost for producing the good, denoted by $c$. Further, $c(\cdot)$ is twice differentiable, strictly increasing and strictly convex in $q$. That is, $c^{\prime}>0$ and $c^{\prime \prime}>0$. Quality in this model is a broad notion that encompasses any feature that may affect a consumer's willingness to pay for a good. These could include features intrinsic to the product itself (such as durability and functionality), or those related to the quality of the shopping experience, or the service level provided by the firm (such as warranties and customer service). Quality is observed perfectly by all consumers.

Given the quality levels and prices offered by the two firms, consumers make their choices. Suppose, in the benchmark case of uniform pricing, Firm 1 offers $\left(q_{1}, p_{1}\right)$ and Firm 2 offers $\left(q_{2}, p_{2}\right)$. There will be a subset of consumers (including null) who buy from each 
Figure 1 Consumers' Purchasing Decision by Consumer Type $(\theta)$

Buy neither product

firm, 1 and 2. The profit of firm $j$ is its market coverage times $\left(p_{j}-c\left(q_{j}\right)\right)$. In the case of PP, we allow one or both firms to be exogenously equipped with a technology that perfectly reveals the consumer's type before the price is disclosed to the consumer. Both firms know which firm has PP before the game is played. While the firm offers the same quality product to all consumers, it can choose a personalized price for each consumer. In this case, firm $j$ 's profit from consumer $\theta$ is $\left(p_{j}(\theta)-c\left(q_{j}\right)\right)$. Let $c_{j}$ denote $c\left(q_{j}\right)$. In practice, implementing PP may well incur some fixed costs. However, if such costs are independent of the quality of the product being offered by the firm, they do not affect the qualitative nature of the results. For simplicity, we treat these costs as zero. ${ }^{8}$ We consider pure-strategy subgame-perfect equilibria of this threestage game. That is, for any strategies the firms may choose at Stages 1 and 2, consumers behave optimally at Stage 3. Firms, in turn, not only anticipate this behavior, but also choose optimal prices, given quality levels, at Stage 2 . The subgame-perfect equilibrium is determined by backward induction, starting with Stage 3.

Consider the case when neither firm has access to PP (we call this the no-PP case). As shown by Moorthy (1988), in equilibrium at Stage 3, the firms share the market in the following manner. ${ }^{9}$ There exist threshold consumers $\theta_{h}$ and $\theta_{l}$ such that consumers with valuations greater than a cutoff level $\theta_{h}$ and less than 1 purchase product $h$; and those with valuations between a second cutoff level $\theta_{l}$ and $\theta_{h}$ purchase product $l$. This situation is depicted in Figure 1. The details of the profit equations and reaction functions are provided in $\S 1.1$ of the appendix.

The same intuition also applies in the case in which one or both firms have PP. Of course, for the equilibrium to have these properties with both firms existing, it must be that $0<\theta_{l}<\theta_{h}<1$. In solving the various cases, we show that an equilibrium with these properties exists.

\section{Duopoly with Personalized Pricing}

Suppose first that only one firm has PP. There are two equilibria in this case: one in which the PP firm has a

\footnotetext{
${ }^{8}$ In $\S 4$, we provide guidelines as to when firms should or should not invest in PP if the fixed costs are nonzero.

${ }^{9}$ Moorthy assumes quadratic costs, but this result depends only on consumer preferences.
}

lower quality than the other firm, and a second one in which the PP firm has a higher quality. We consider each of these, and then examine the case in which both firms have PP.

3.1. Personalized Pricing Firm Offers Low Quality We use the superscript $l$ to denote this case, while the subscripts $h, l$ denote the firms. In the spirit of backward induction, suppose that firms choose qualities $q_{h}, q_{l}$ at Stage 1, and consider Stage 2 first. Let $p_{h}^{l}, p_{l}^{l}(\theta)$ denote the optimal prices chosen at Stage 2 (as functions of $q_{h}, q_{l}$ ). Similarly, let $\pi_{l}^{h}, \pi_{l}^{l}$ denote the profit functions, as functions of $q_{h}$ and $q_{l}$ alone (that is, after substituting in the optimal Stage 2 prices). For brevity, in the notation we often suppress the dependence of these functions on $q_{h}, q_{l}$ (this dependence is clear in the expressions exhibited below). We use $q_{1}^{h}$ and $q_{l}^{l}$ to denote equilibrium qualities chosen at Stage 1. A notation guide is provided in the appendix.

We restrict attention to qualities $q$ that satisfy $c(q)<q$. The rationale for this is as follows: The consumer with $\theta=1$ is the one who is willing to pay the most for a given product with quality $q$. This consumer is willing to pay up to $q$ for the product. If $c(q) \geq q$, a firm cannot obtain a positive market share unless it also makes a loss. Regardless of the quality it chooses at Stage 1, it can always prevent a loss by charging consumers a price $p \geq q$, which ensures zero sales. Hence, we only consider qualities with $c(q)<q$. Because the cost function is convex, it is sufficient to impose this condition on the higher-quality firm.

In this case, firm $l$ knows the type of each consumer, and hence can offer prices that depend on $\theta$. It must be willing to offer a price as low as its marginal cost, $c_{l}=c\left(q_{l}\right)$, to each consumer, if necessary. Further, consistent with price discrimination, it will charge each consumer as high a price as it can. At Stage 3, firm $h$ (which does not have PP) will operate in a market segment $\left[\theta_{h}, 1\right]$, and firm $l$ in a market segment $\left[\theta_{l}, \theta_{h}\right]$. Consider first the location of the marginal consumer $\theta_{h}$, who is indifferent between buying from either firm. This consumer must obtain the same utility from either product. If $p_{l}^{l}\left(\theta_{h}\right)>c_{l}$, then firm $l$ would lower its price for this consumer to ensure that he strictly prefers to buy product $l$. Hence, it must be that $p_{l}^{l}\left(\theta_{h}\right)=c_{l}$. Therefore, this consumer is defined by $\theta_{h} q_{h}-p_{h}^{l}=\theta_{h} q_{l}-c_{l}$ or $\theta_{h}=\left(p_{h}^{l}-c_{l}\right) /\left(q_{h}-q_{l}\right)$. For now, the qualities could be arbitrary, so define $\theta_{h}=\min \left\{\left(p_{h}^{l}-c_{l}\right) /\left(q_{h}-q_{l}\right), 1\right\}$. Similarly, $\theta_{l}$ is defined as the consumer who is indifferent between buying product $l$ and not consuming at all. Again, it must be that $p_{l}^{l}\left(\theta_{l}\right)=c_{l}$, else firm $l$ could increase its profit by reducing its price for this consumer. Hence, $\theta_{l} q_{l}-$ $c_{l}=0$ or $\theta_{l}=c_{l} / q_{l}>0$. Finally, the consumer who is exactly indifferent between not buying at all and buying from firm $h$ is defined as $\hat{\theta}=p_{h}^{l} / q_{h}$. At arbitrary 
qualities, it may be that this leads to $\hat{\theta}>1$, so define $\hat{\theta}=\min \left\{p_{h}^{l} / q_{h}, 1\right\}$.

In the pricing subgame, we further restrict attention to prices that satisfy $p \geq c(q)$ for a given quality $q$. No firm is willing to sell to consumers at a price less than its marginal cost (because this results in a loss). However, for some qualities, there exist equilibria in the subgame at which firm $h$ may price below its cost, but makes zero sales. Firm $h$ earns zero profits across these equilibria, so we consider the equilibrium in which it prices no lower than its cost, $c\left(q_{h}\right)$.

Now, consider Stage 2. Suppose that firms have chosen qualities $q_{h}, q_{l}$ at Stage 1 . We show that, at Stage 2, the optimal price function of firm $l$ is nonmonotonic in consumer type; that is, it charges some high-valuation consumers less than it charges some low-valuation consumers.

Proposition 1. Suppose that firms choose any qualities $q_{h}$ and $q_{l}$ at Stage 1 , with associated costs $c_{h}=c\left(q_{h}\right)$ and $c_{l}=c\left(q_{l}\right)$, that satisfy (i) $q_{l}<q_{h}$ and (ii) $c_{h}<q_{h}$. In the equilibrium of the pricing subgame starting at Stage 2, we have $0<\theta_{l}<\theta_{h} \leq 1$. Further,

(a) firm $h$ sets a price

$$
p_{h}^{l}=\max \left\{(1 / 2)\left(q_{h}-q_{l}+c_{h}+c_{l}\right), c_{h}\right\} ;
$$

(b) firm $l$ sets a price $p_{l}^{l}(\theta)$ that is nonmonotonic in a consumer's valuation $\theta$, such that some higher-valuation consumers obtain lower prices than some lower-valuation ones. Specifically,

$$
p_{l}^{l}(\theta)= \begin{cases}\theta q_{l} & \text { if } \theta \in\left[\theta_{l}, \hat{\theta}\right], \\ p_{h}^{l}-\theta\left(q_{h}-q_{l}\right) & \text { if } \theta \in\left(\hat{\theta}, \theta_{h}\right], \\ c_{l} & \text { if } \theta \in[0, \hat{\theta}) \quad \text { or } \quad \theta \in\left(\theta_{h}, 1\right] .\end{cases}
$$

This situation is depicted in Figure 2. The intuition is that in the market segment $[0, \hat{\theta}]$, firm $l$ faces no competition from firm $h$. These consumers are not willing to buy product $h$ at the offered quality and price. Hence, firm $l$ is able to extract their entire consumer surplus. However, consumers in the range $[\hat{\theta}, 1]$ obtain a positive utility from consuming product $h$ as well. Hence, firm $l$ faces competition in this

Figure 2 Prices of Firms / and $h$ When Firm / Alone Has Personalized Pricing

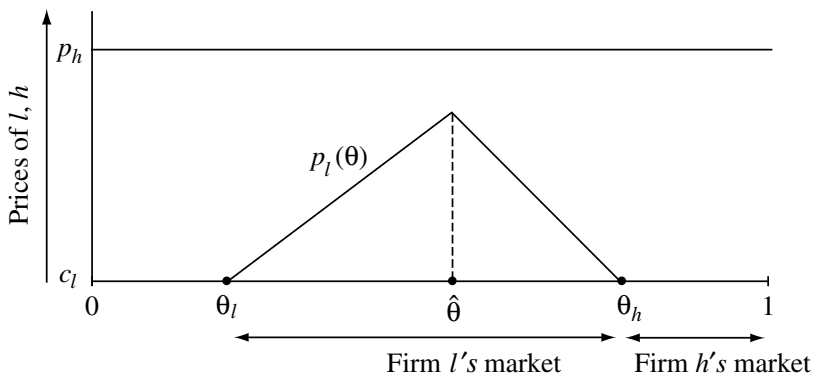

range, and must offer consumers at least as high a surplus as firm $h$ to induce them to buy product $l$. Thus, the threat of latent competition from firm $h$ provides these consumers with a positive surplus that is monotonically increasing in their valuations.

Now, consider the choice of qualities at Stage 1. In Lemma 1 in the appendix, we show that at the equilibrium qualities, given the prices exhibited in Proposition 1 , the threshold consumer types satisfy $0<\theta_{l}<$ $\theta_{h}<1$. Hence, we ignore the Kuhn-Tucker constraints implied by these conditions, and focus on the interior solution.

Suppose that firm $l$ chooses $q_{l}$ and firm $h$ chooses $q_{h}$. Further, suppose that both firms choose optimal prices (as given by Proposition 1), given the two qualities. Then, the profit functions of the two firms are

$$
\begin{gathered}
\pi_{l}^{l}\left(q_{h}, q_{l}\right)=\int_{\theta_{l}}^{\hat{\theta}}\left(\theta q_{l}-c_{l}\right) d \theta+\int_{\hat{\theta}}^{\theta_{h}}\left(p_{h}^{l}-\theta\left(q_{h}-q_{l}\right)-c_{l}\right) d \theta \\
=\frac{\left(p_{h}^{l} q_{l}-q_{h} c_{l}\right)^{2}}{2\left(q_{h}-q_{l}\right) q_{h} q_{l}} \\
\pi_{h}^{l}\left(q_{h}, q_{l}\right)=\left(p_{h}^{l}-c_{h}\right)\left(1-\theta_{h}\left(p_{h}^{l}, q_{h}, c_{l}, q_{l}\right)\right) \\
=\frac{\left(q_{h}-q_{l}-c_{h}+c_{l}\right)^{2}}{2\left(q_{h}-q_{l}\right)}
\end{gathered}
$$

When firm $l$ adopts PP, the competitive response of firm $h$ is to reduce its price. This is the "price competition effect." PP allows firm $l$ to set a price as low as marginal cost for a particular consumer, to induce him to buy product $l$. This leads to an immediate increase in the market coverage of firm $l$, both amongst lowvaluation consumers, and those who were previously buying product $h$. In response to this heightened competition from firm $l$, firm $h$ strategically reduces its price. This response of firm $h$, in turn, induces firm $l$ to lower its own quality to reduce the competition with firm $h$ and tap some more uncontested marginal consumers on the left. We demonstrate these effects in Lemma 2 of the appendix, which also derives the reaction functions for the two firms.

Of course, in equilibrium, both firms change their qualities from the no-PP case. If the cost function is quadratic, we show that both firms reduce their qualities.

Proposition 2. Suppose that the cost function is quadratic; that is, $c(q)=A q^{2}$. In equilibrium, when firm $l$ adopts $P P$, both firms reduce their qualities compared to the no-PP case. In particular, $q_{h}^{l}=0.388 / A$ and $q_{l}^{l}=0.164 / A$.

Because analytic solutions are infeasible in the general case, we numerically solve for qualities using a cost function $c(q)=q^{\alpha}$, where $\alpha>1$. In the numeric solution, we check that the constraints $0<\theta_{l}<\theta_{h}<1$ 
Figure 3 Equilibrium Qualities of Firms $h$ (Left) and / (Right) with $c(q)=q^{\alpha}$

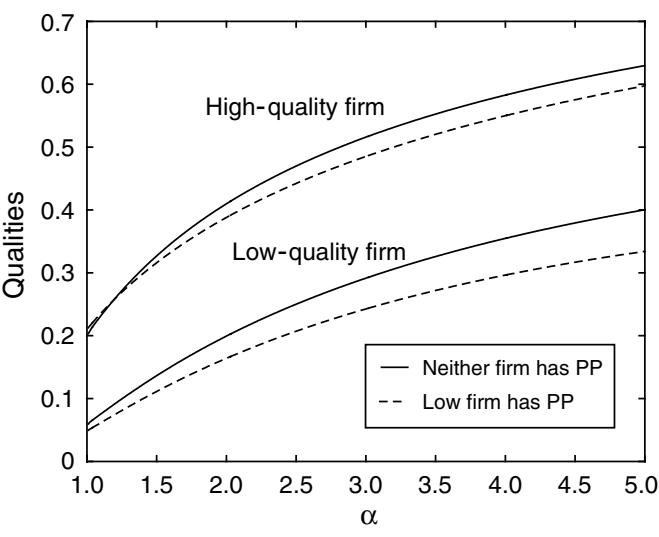

are satisfied for each $\alpha$ (so that each firm has a positive market share in all cases). The results are shown in Figure $3{ }^{10}$ If the cost function is not too convex (in particular, $\alpha \leq 1.2$ ), firm $h$ chooses a higher quality in equilibrium. Conversely, if the cost function is highly convex $(\alpha>1.2)$, it chooses a lower quality.

The intuition for this is as follows. PP allows firm $l$ to charge a price as low as its cost, $c_{l}$. This lets it penetrate an untapped market segment with lower valuations than it is currently serving, as well as make some headway into the market served by firm $h$. This is the "market coverage effect." Firm $h$ has two competitive responses to this. First, as a result of the price competition effect, it reduces its price. Second, when costs are sufficiently convex, it reduces its quality. By moving towards the low-quality firm, $h$ increases the uncontested portion of its market. This further induces firm $l$ to reduce its own quality to mitigate the more aggressive competition from firm $h$. However, if costs are almost linear (i.e., for low values of $\alpha$ ), firm $h$ increases its quality in equilibrium and increases its price. Though this entails a lower market coverage, the nature of the cost function implies that the profit per unit sold is higher. This "cost of quality effect" is also critical in determining the new equilibrium qualities and prices.

\subsection{Personalized Pricing Firm Offers High Quality}

We use the superscript $h$ to denote this case. In this case, firm $h$ knows the type of each consumer, and hence is willing to price as low as $p_{h}^{h}(\theta)=c_{h}$ if need be. ${ }^{11}$ The threshold consumer $\theta_{h}$ obtains the same util-

\footnotetext{
${ }^{10}$ A description of the technique used to solve for the equilibrium in the no-PP case is contained in the technical appendix.

${ }^{11}$ Again, for brevity, we suppress the dependence of the optimal price functions $p_{h}^{h}, p_{l}^{h}$ on $q_{h}, q_{l}$.
}

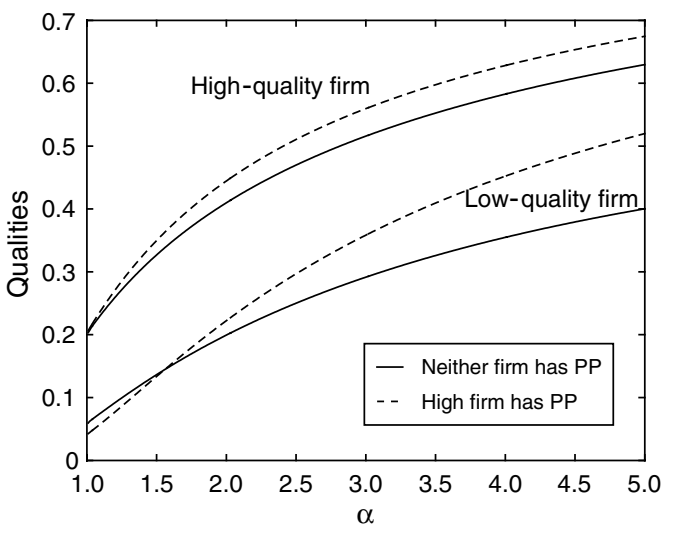

ity from either product. ${ }^{12}$ If $p_{h}^{h}\left(\theta_{h}\right)>c_{l}$, then firm $l$ would lower its price for this consumer to ensure that he strictly prefers to buy product $l$. Hence, it must be that $p_{h}^{h}\left(\theta_{h}\right)=c_{l}$. Therefore, this consumer is defined by $\theta_{h}=\left(c_{h}-p_{l}^{h}\right) /\left(q_{h}-q_{l}\right)$. Similarly, $\theta_{l}$ is defined by the consumer indifferent between buying product $l$ and not consuming at all. Hence, $\theta_{l}=p_{l}^{h} / q_{l}$. In contrast to the low-PP case, when firm $h$ adopts PP, it charges a price monotonic in consumer valuations.

Proposition 3. Suppose that firms choose any qualities $q_{h}>q_{l}$ at Stage 1, with associated costs $c_{h}=c\left(q_{h}\right)$ and $c_{l}=c\left(q_{l}\right)$, that satisfy (i) $q_{l}<q_{h}$ and (ii) $c_{h}<q_{h}$. In the equilibrium of the pricing subgame starting at Stage 2, we have $0<\theta_{l}<\theta_{h} \leq 1$. Further,

(a) The optimal price of firm $l$ is lower than $c_{h}$, the marginal cost of firm $h$. Specifically, firm $l$ sets

$p_{l}^{h}= \begin{cases}\frac{1}{2}\left(c_{l}+\frac{q_{l}}{q_{h}} c_{h}\right) & \text { if } \frac{1}{2}\left(\frac{c_{h}-c_{l}}{q_{h}-q_{l}}+\frac{c_{h}}{q_{h}}\right) \leq 1, \\ \min \left\{c_{h}-\left(q_{h}-q_{l}\right), \frac{c_{l}+q_{l}}{2}\right\} & \text { otherwise. }\end{cases}$

(b) Over the market it serves, firm $h$ charges an optimal price monotonically increasing in consumer valuations. Specifically, firm $h$ sets

$$
p_{h}^{h}(\theta)= \begin{cases}c_{h} & \text { if } \theta \in\left[0, \theta_{h}\right], \\ \frac{1}{2}\left(c_{l}+\frac{q_{l}}{q_{h}} c_{h}\right)+\theta\left(q_{h}-q_{l}\right) & \text { if } \theta \in\left(\theta_{h}, 1\right] .\end{cases}
$$

Firm $h$ charges a monotonically increasing price because it faces no competitive threat from firm $l$ in the region $\left[\theta_{h}, 1\right]$. Interestingly, firm $l$ 's price is lower than even the marginal cost of firm $h$, i.e., $p_{l}^{h}<c_{h}$. This pricing policy enables it to serve a sizable segment of

\footnotetext{
${ }^{12}$ As in the low-PP case, we solve for an interior solution, with $0<\theta_{l}<\theta_{h}<1$. We show in Lemma 3 in the appendix that the equilibrium must satisfy this condition.
} 
the market, despite being a low-quality firm and not having PP.

Now consider the choice of qualities of Stage 1. Incorporating the optimal Stage 2 prices leads to the following profit functions for the firms:

$$
\begin{gathered}
\pi_{l}^{h}\left(q_{h}, q_{l}\right)=\left(\theta_{h}-\theta_{l}\right)\left(p_{l}^{h}-c_{l}\right)=\frac{\left(c_{h} q_{l}-q_{h} c_{l}\right)^{2}}{2 q_{h} q_{l}\left(q_{h}-q_{l}\right)}, \\
\pi_{h}^{h}\left(q_{h}, q_{l}\right)=\int_{\theta_{h}}^{1}\left(p_{h}^{h}(\theta)-c_{h}\right) d \theta=\frac{\left(p_{l}^{h}+q_{h}-q_{l}-c_{h}\right)^{2}}{2\left(q_{h}-q_{l}\right)} .
\end{gathered}
$$

In this case, too, the price-competition effect works in the same direction: The firm that does not have PP (here, firm $l$ ) reduces its price to compete more effectively. In response to this "price-competition effect," firm $h$ raises its quality. We demonstrate this in Lemma 4 in the appendix.

Of course, in equilibrium, both firms change their qualities from the no-PP case. We first demonstrate that with quadratic costs, both firms raise their qualities.

Proposition 4. Suppose that the cost function is quadratic; that is, $c(q)=A q^{2}$. In equilibrium, when firm $h$ adopts $P P$, both firms raise their qualities compared to the no-PP case. In particular, $q_{h}^{h}=0.444 / A$ and $q_{l}^{h}=0.222 / A$.

However, this is not true for all degrees of convexity of the cost function. As in the low-PP case, if the cost function is not too convex (in particular, $\alpha \leq 1.55)$, firm $l$ chooses a lower quality in equilibrium. Conversely, if the cost function is highly convex $(\alpha>1.55)$, it chooses a higher quality (see Figure 3).

Thus, for a wide range of $\alpha$, both firms increase their qualities compared to the no-PP case. Here, the market coverage effect benefits firm $h$, which can penetrate into the market of firm $l$. The competitive response of firm $l$ takes two dimensions: It reduces its price (the price-competition effect), and also increases its quality (to come closer to firm $h$ ). This, in turn, induces firm $h$ to increase its own quality to avoid head-to-head competition. As in the low-PP case, if costs are close to linear (i.e., for low values of $\alpha$ ), the firm without PP moves further away in quality. That is, firm $l$ reduces its quality, with a corresponding reduction in price. This results in lower market coverage, but a higher profit per unit, due to the costof-quality effect. Therefore, starting from the no-PP case, if the cost function is convex enough, the non-PP firm seeks to reduce quality differentiation and come closer to the PP firm in the quality space. That is, if the PP firm has a low quality, in equilibrium both firms end up with lower qualities than previously. The converse outcome occurs if the PP firm chooses high quality; that is, both firms end up with higher qualities. Further, the firm without PP offers a lower price than the corresponding price in the no-PP case.

\subsection{Both Firms Have Personalized Pricing}

We denote this case with the superscript $b$. Suppose that the firms choose qualities $q_{h}$ and $q_{l}$ at Stage 1 . Then, $\theta_{h}=\left(c_{h}-c_{l}\right) /\left(q_{h}-q_{l}\right), \theta_{l}=c_{l} / q_{l}$, and $\hat{\theta}=c_{h} / q_{h}$. Recall that firm $h$ sells to consumers in the region $\left[\theta_{h}, 1\right]$ and firm $l$ in the region $\left[\theta_{l}, \theta_{h}\right]$. As in the low-PP case, $\hat{\theta}$ represents the point beyond which firms compete for consumers, so that consumers in the region $\left[\theta_{l}, \hat{\theta}\right]$ are not willing to buy good $h$ at any price $c_{h}$ or higher. ${ }^{13}$

Consider Stage 2 of this game, where the firms choose their price schedule, given qualities $q_{h}, q_{l}$. Let $p_{h}^{b}(\theta)$ be the optimal price charged by firm $h$ to the consumer of type $\theta$. This is the price at which he is exactly indifferent between buying the low-quality product at $c_{l}$ (the lowest price firm $l$ is willing to charge) and the high-quality product $h$ at $p_{h}^{b}(\theta)$. Therefore, $\theta q_{h}-p_{h}^{b}(\theta)=\theta q_{l}-c_{l}$ or $p_{h}^{b}(\theta)=c_{l}+\theta\left(q_{h}-q_{l}\right)$. As in the high-PP case, this price is strictly increasing in $\theta$.

Consider the price charged by firm $l$. The pricing function is similar to the one in the low-PP case, with the one difference that firm $h$ is willing to price as low as $c_{h}$ to any consumer. Hence, the optimal price function for firm $l$ is $p_{l}^{b}(\theta)=\theta q_{l}$ for $\theta \in\left[\theta_{l}, \hat{\theta}\right]$ and $p_{l}^{b}(\theta)=$ $c_{h}-\theta_{h}\left(q_{h}-q_{l}\right)$ for $\theta \in\left[\hat{\theta}, \theta_{h}\right]$. As before, in the latter region, the price of firm $l$ is declining in a consumer's willingness to pay. Stepping back to Stage 1, we incorporate the optimal Stage 2 prices into the firms' profit functions to obtain

$$
\begin{gathered}
\pi_{h}^{b}\left(q_{h}, q_{l}\right)=\int_{\theta_{h}}^{1}\left(c_{l}+\theta\left(q_{h}-q_{l}\right)-c_{h}\right) d \theta \\
=\frac{\left(q_{h}-q_{l}-c_{h}+c_{l}\right)^{2}}{2\left(q_{h}-q_{l}\right)} \\
\pi_{l}^{b}\left(q_{h}, q_{l}\right)=\int_{\theta_{l}}^{\hat{\theta}}\left(\theta q_{l}-c_{l}\right) d \theta+\int_{\hat{\theta}}^{\theta_{h}}\left(c_{h}-\theta\left(q_{h}-q_{l}\right)-c_{l}\right) d \theta \\
=\frac{\left(c_{h} q_{l}-q_{h} c_{l}\right)^{2}}{2 q_{h} q_{l}\left(q_{h}-q_{l}\right)} .
\end{gathered}
$$

Comparing Equations (5) and (2), we observe that the profit function of firm $h$, when both firms have PP, is exactly the same as in the case when only firm $l$ has PP. Hence, firm $h$ 's reaction function in the two cases is the same as well. Similarly, comparing Equations (6) and (3), the profit function of firm $l$, when both firms have PP, is exactly the same as in the case when only firm $h$ has PP. Hence, $l$ 's reaction function in the two cases is the same as well. The analysis of the previous two cases can now be directly used when both firms have PP.

We show that when both firms have PP, both firms choose a lower quality than when only firm $h$ has PP.

\footnotetext{
${ }^{13}$ We show in the proof of Proposition 5 in the online appendix that the equilibrium satisfies $0<\theta_{l}<\theta_{h}<1$.
} 
Table 1 Summary of Equilibrium Results When $c(q)=A q^{2}$

\begin{tabular}{|c|c|c|c|c|c|c|c|c|}
\hline \multirow[b]{2}{*}{ Firm } & \multicolumn{2}{|c|}{ Neither firm has PP } & \multicolumn{2}{|c|}{ Low-PP case } & \multicolumn{2}{|c|}{ High-PP case } & \multicolumn{2}{|c|}{ Both firms have PP } \\
\hline & $h$ & l & $h$ & l & $h$ & l & $h$ & l \\
\hline Quality & $0.410 / A$ & $0.199 / A$ & $0.388 / A$ & $0.164 / A$ & $0.444 / A$ & $0.222 / A$ & $0.4 / A$ & $0.2 / A$ \\
\hline Market coverage & 0.279 & 0.345 & 0.224 & 0.612 & $0.444^{\prime}$ & 0.222 & 0.4 & $0.4^{\prime}$ \\
\hline Average price & $0.227 / A$ & $0.075 / A$ & $0.201 / A$ & $0.056 / A$ & $0.247 / A$ & $0.074 / A$ & $0.2 / A$ & $0.06 / A$ \\
\hline Profit & $0.016 / A$ & $0.012 / A$ & $0.011 / A$ & $0.018 / A$ & $0.022 / A$ & $0.006 / A$ & $0.016 / A$ & $0.008 / A$ \\
\hline Consumer surplus & \multicolumn{2}{|c|}{$0.047 / A$} & \multicolumn{2}{|c|}{$0.045 / A$} & \multicolumn{2}{|c|}{$0.049 / A$} & \multicolumn{2}{|c|}{$0.12 / A$} \\
\hline
\end{tabular}

Note that this result does not depend on additional restrictions on the cost function. In comparing the qualities to the case when only firm $l$ has PP, we find that both qualities are higher when the cost function is convex enough, but lower when the cost function is not too convex. Numerically, for the function $c(q)=q^{\alpha}$, when $\alpha>1.3$, both qualities are higher than in the low-PP case. We analytically prove this latter result for the quadratic cost function.

Proposition 5. Consider the case in which both firms have PP.

(i) In equilibrium, both firms offer a lower quality than in the case where only firm $h$ has PP. That is, $q_{h}^{b}<q_{h}^{h}$ and $q_{l}^{b}<q_{l}^{h}$.

(ii) Suppose that the cost function is quadratic, so $c(q)=A q^{2}$. Then, in equilibrium, both firms offer a higher quality than in the case where only firm $l$ has PP. That is, $q_{h}^{b}=0.4 / A>q_{h}^{l}$ and $q_{l}^{b}=0.2 / A>q_{l}^{l}$.

When costs are quadratic, compared to the case when neither firm had PP, in equilibrium the highquality firm lowers its quality and the low-quality firm raises its quality. Thus, both firms actually come closer to each other in quality. A subtle consequence of both firms having PP is that the increase in pricing flexibility levels the playing field. Because both firms can now price at marginal cost for the threshold customer, the price competition effect leads to intensified competition for market share. Further, both have an incentive to compete more aggressively, so the relative product differentiation between the two firms decreases, which in turn increases the market coverage of each firm. However, for increasingly convex cost structures, the additional burden of the cost-ofquality effect leaves both firms worse off. The intensified price competition implies that consumers are better off.

\section{Firm Profits and Consumer Surplus}

In this section, we examine which firms are likely to adopt PP and the resultant consumer welfare. Suppose that neither firm has PP. We assume that after one or both firms adopt PP, the quality rankings of the firms do not change. That is, the low-quality firm, when neither firm had PP, remains the low-quality firm when one or both firms have PP. Quality levels are tantamount to brand equity, and significant changes to quality are likely to be costly. This is especially true when quality rankings are reversed. By contrast, local or marginal changes to quality can be made in a continuous fashion. Hence, we now consider firm $l$ acquiring PP, or firm $h$ acquiring PP, or both. First, consider the quadratic cost case, with $c(q)=A q^{2}$. In Table 1, we exhibit equilibria under different settings for this case.

The consumer surplus (CS) shown above is defined in each of the four cases as

$$
\mathrm{CS}=\int_{\theta_{l}}^{\theta_{h}}\left(\theta q_{l}-p_{l}(\theta)\right) d \theta+\int_{\theta_{h}}^{1}\left(\theta q_{h}-p_{h}(\theta)\right) d \theta,
$$

where $p_{l}(\theta)$ and $p_{h}(\theta)$ are, respectively, the prices paid in equilibrium by a consumer of type $\theta$ buying good $l$ and good $h{ }^{14}$ For example, in the case when the PP firm has low quality, we have $p_{h}(\theta)=p_{h}^{l}$, which is independent of $\theta$, and $p_{l}(\theta)=p_{l}^{l}(\theta)$, as given in Proposition 1.

Note that the results in the case when neither firm has PP correspond exactly to those of Moorthy (1991). The average price displayed in the table is the average of the prices paid by different consumers for the good. In the case when neither firm has PP, all consumers pay the same price. When both firms have PP, due to the intensified competition, the average price of both firms is the lowest across all cases. Further, the overall market coverage is at its highest. Hence, CS is maximized in this case.

As Table 1 shows, both firms have an incentive to adopt PP when costs are quadratic, regardless of whether the other firm also has PP. However, the firms are trapped in a prisoners' dilemma: If both firms adopt PP, their profits are each lower than in the no-PP case. Even though there is a market coverage effect that boosts market share, the deleterious impact of the price competition effect is that the average price of each sale is lower. Further, due to the costof-quality effect the profits dip, leaving both firms worse off as a result. We summarize the quadratic case as follows. The proof follows directly by comparison across the columns in Table 1.

\footnotetext{
${ }^{14}$ Because this CS expression applies to each of the four cases, we omit the superscript on prices and qualities.
} 
Figure 4 Profit of Firm / When Firm $h$ Does Not (Left) and Does (Right) Have Personalized Pricing

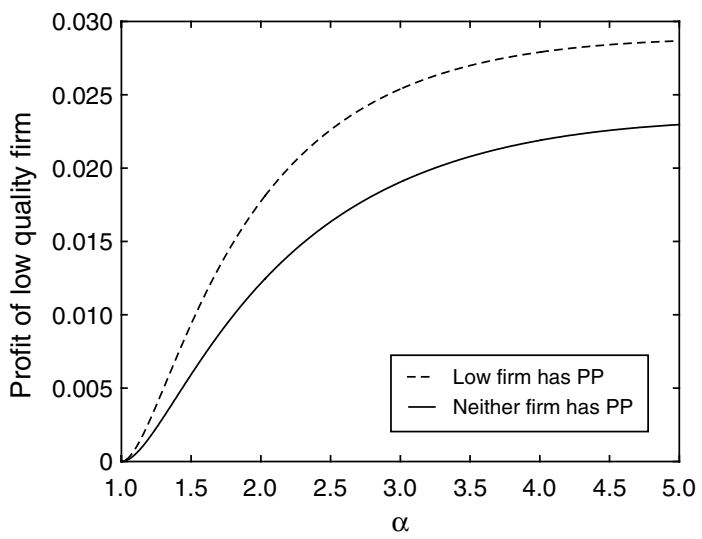

Proposition 6. Suppose that costs are quadratic, so $c(q)=A q^{2}$. Then,

(i) If one firm alone adopts $P P$, its profit increases compared to the case when neither firm has PP. However, if both firms have PP, each firm has lower profits than in the no-PP case.

(ii) CS is highest when both firms have PP. Further, it is higher when only firm $h$ has $P P$, compared to the cases when either firm $l$ alone or neither firm has PP.

Next, consider the case $c(q)=q^{\alpha}$, where $\alpha>1$. As before, we numerically compare equilibria across the different cases. We find that CS remains highest in the case when both firms have PP. This points out the benefits of competition when there is perfect price discrimination, in contrast to the scenario where there is only a monopolist, which results in zero CS. ${ }^{15}$

Observation 1. For all $\alpha>1$, CS is higher when both firms have PP, as compared to any of the other cases.

When both firms have PP, firm $h$ charges a price $p_{h}^{b}(\theta)=c_{l}+\theta\left(q_{h}-q_{l}\right)$ to its consumers. Compare this to the price it charges when firm $l$ does not have PP: $p_{h}^{h}(\theta)=p_{l}^{h}+\theta\left(q_{h}-q_{l}\right)$. If firm $l$ now adopts PP, the greater competition leads to a lower price for consumers of firm $h$, and a corresponding increase in welfare. CS falls compared to the no-PP case if the PP firm has low quality, but rises if the PP firm has high quality. When firm $l$ has PP, it extends its market reach to a segment previously untapped because it can price as low as marginal cost. However, a segment of firm l's consumers receive no surplus, because they pay a price exactly equal to their willingness to pay. Conversely, if firm $h$ has PP, it faces competition from firm $l$ throughout its market segment, and is forced to concede some surplus to consumers.

Observation 2. For $\alpha \in[1,4]$, it is a dominant strategy for firm $l$ to adopt PP. That is, regardless of whether firm $h$ has PP, firm $l$ should adopt PP.

${ }^{15}$ Bhaskar and To (2004) obtain similar results in their framework.

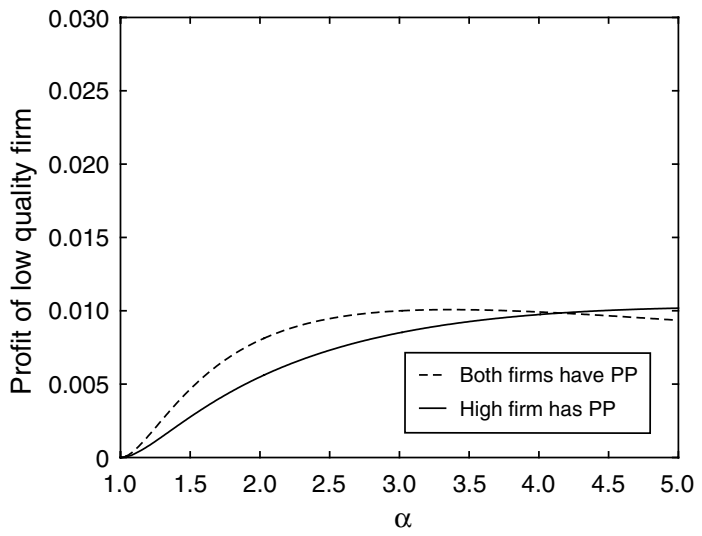

Figure 4 demonstrates the increase in profit to firm $l$ when it adopts PP. The figure on the left illustrates the case of neither firm having PP, and the figure on the right, the case of firm $h$ having PP. We emphasize that the cost of acquiring a resource to enable PP is not factored into this calculation. Such a cost can be incorporated as follows. The vertical gap between the dashed and solid line indicates the gain to firm $l$ from PP. It will adopt PP if and only if this gap exceeds the fixed cost of adopting PP.

ObSERVATION 3. Regardless of whether firm $l$ has PP, firm $h$ should adopt PP only if the cost function is not too convex. In particular, there exists an $\widehat{\alpha} \in$ $[2.5,3]$ such that if $\alpha>\widehat{\alpha}$ and firm $h$ adopts PP, its profits decrease.

Figure 5 demonstrates this result. How can the profit of firm $h$ decrease when it adopts PP? Recall that when firm $h$ adopts PP and firm $l$ does not have PP, firm $l$ responds by reducing its price. This induces firm $h$ to increase its quality. Increasing quality is especially costly when the cost function is steep; indeed, it is costly enough in this case to outweigh the benefits of charging consumers according to their willingness to pay. A similar intuition holds when firm $l$ has PP. If firm $h$ adopts PP in this situation, the new equilibrium sees both firms at a higher quality, which is correspondingly costly for firm $h$. Again, note that this result does not factor in a cost for implementing PP. With such a cost, firm $h$ has even less incentive to adopt PP. Together, these results imply the following.

ObSERvation 4. PP by both firms need not lead to a prisoner's dilemma situation in which all firms are worse off. If both firms adopt PP, then, for a lower level of convexity of the cost function, both firms have higher profits compared to the case when neither firm has PP. However, the market shares increase for both firms, for all $\alpha$.

The result on profits can be seen by comparing the profits of the two firms in Figures 4 and 5, between 
Figure 5 Profit of Firm $h$ When Firm / Does Not (Left) and Does (Right) Have Personalized Pricing

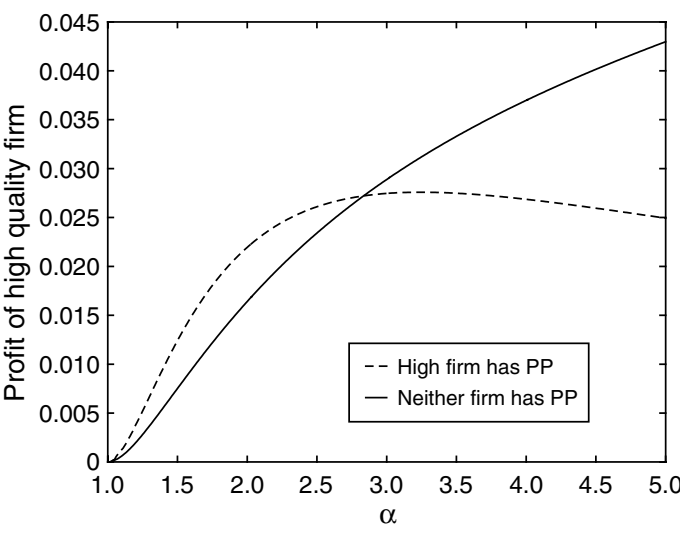

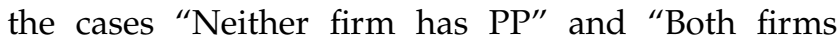
have PP." PP increases the pricing flexibility of both firms. An obvious consequence of this is more intense price competition. However, because the firms also respond by strategically changing qualities, the costof-quality effect plays a crucial role in determining the net change in profits. This ensures that PP does not invariably lead to a prisoner's dilemma.

\section{Managerial Implications and Conclusions}

The practice of PP is important in both offline and online channels. Our results show that an appropriate pricing strategy must take into account both consumers' willingness to pay and competition in a particular market segment. Ignoring either one can result in lower profits. In our model, if the low-quality firm deploys PP, it is optimal for it to use a nonmonotonic price schedule. Thus, some high-valuation consumers are charged lower prices than some lowervaluation consumers. An example of such pricing comes from the hardware industry for RISC/NT servers and high-end workstations wherein it is quite common to charge different prices to different customers for the same quality and same quantity. Large customers are able to extract huge discounts, despite valuing the product very highly. On the other hand, smaller enterprises obtain lower discounts because no other firm competes for their demand (because the profit margins are much lower). In the latter segment, manufacturers often price according to the customers' willingness to pay and in the process capture most of their surplus. Consequently, they are able to extract higher profits from some undercontested customers. Conversely, their margins are also squeezed by some large customers who play the firms against each other and win price concessions.

Our model also sheds light on the different product quality choices made by firms, given that one or both firms implement PP. When a low-quality

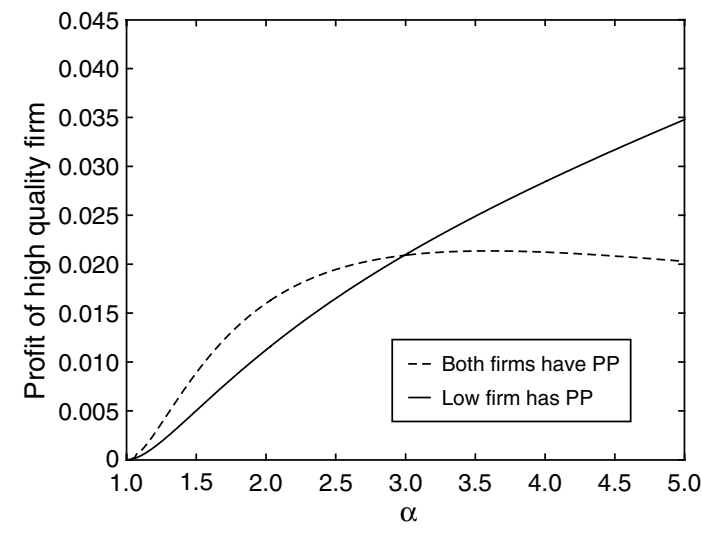

firm adopts PP, both firms reduce their quality levels in equilibrium. In the IT hardware industry, this is often done through stripping off some valueadded customer service, such as next-day on-site repair versus same-day 8 -hour repair, or a $99 \%$ uptime guarantee versus $99.95 \% .{ }^{16}$ Conversely, if the high-quality firm adopts PP, both firms should augment the quality levels of their offerings by providing additional product features or services. For instance, HP differentiates itself by providing higher quality, new generation Web-based applications, as well as clustering and security management software embedded in the same hardware box. (See http:// www.hp.com / hpinfo / execteam / speeches / fiorina / oracleapps_02.html.)

The critical issue for managers in vertically differentiated industries to keep in mind in adopting PP is the interplay between two countervailing effects: increased market coverage and intensified competition, given the convexity of the cost function. The increase in market coverage makes PP attractive. However, aggravated price competition hurts firms' profits. Further, optimal qualities of firms change. Therefore, the net effect of PP also depends on the nature of the cost function. For a lower level of convexity of the cost function, both firms have higher profits compared to the case when neither firm has PP, and hence, are able to avoid the prisoner's dilemma situation. With moderately convex costs, $\alpha \in[1.5,3]$, both low- and high-quality firms have an incentive to adopt PP, regardless of the other firm's actions. However, both firms are better off in the scenario where neither has PP, as compared to both having PP, resulting in a prisoner's dilemma situation. Conversely, if $\alpha>3$, only the low-quality firm will adopt PP because the high-quality firm reduces its own profit by adopting PP.

\footnotetext{
${ }^{16}$ The cost difference to the consumer between, say, a 99\%-uptime guarantee and a $99.95 \%$ guarantee is substantial, so this difference is nontrivial.
} 
Finally, our model also demonstrates that consumers would benefit if higher-quality firms adopt PP. In the event that all firms adopt PP, consumers would benefit the most. Thus, we conclude that, in a competitive scenario, increasing knowledge about consumers' willingness to pay should eventually lead to an overall increase in consumer welfare.

One limitation of this paper is that we only consider a single product offering by each firm, whereas in practice firms often offer multiple products. In the extreme case, one can conceive of firms offering a personalized quality to each consumer, in addition to a personalized price. If both firms have the ability to customize product quality at no additional cost, Bertrand competition for each consumer is inevitable, and both firms will be held to zero profit. Hence, a proper study of customization must therefore incorporate additional features not considered in our model, such as horizontal differentiation or differences in the customization ability of firms. Another limitation is that we assume that a firm with the ability to personalize prices knows the willingness to pay of each consumer for each possible quality level. In practice, of course, we would expect firms to be less certain about the valuations of each consumer for each possible quality level. If the consumer type is observed only with some noise, the intuition of Chen et al. (2001) suggests that price competition may be softened. Thus, our results should be interpreted as the solution to an important limiting case- the case of perfect information. Nevertheless, it is an important case to consider because the effects we identify in this limiting case will also be present in a general case.

An online appendix to this paper is available at http://mansci.pubs.informs.org/ecompanion.html.

\section{Acknowledgments}

The authors thank Christine Parlour, Ram Rao, Kannan Srinivasan, and seminar participants at WISE 2001, ICIS 2002, CIST 2003, Carnegie Mellon University, and New York University for helpful comments. They are grateful to the editor, Jagmohan Raju, the associate editor, and three anonymous reviewers for their comments. All errors remain their own responsibility.

\section{References}

Acquisti, A., H. Varian. 2005. Conditioning prices on purchase history. Marketing Sci. Forthcoming.

Armstrong, M., J. Vickers. 2001. Competitive price discrimination. RAND J. Econom. 32(4) 579-605.
Aron, R., A. Sundararajan, S. Viswanathan. 2005. Intelligent agents in electronic markets for information goods. Decision Support Systems. Forthcoming.

Bhaskar, V., T. To. 2004. Is perfect price discrimination really efficient? An analysis of free entry. RAND J. Econom. 35(4) 762-776.

Chen, Y., G. Iyer. 2002. Consumer addressability and customized pricing. Marketing Sci. 21(2) 197-208.

Chen, Y., C. Narasimhan, Z. Zhang. 2001. Individual marketing with imperfect information. Marketing Sci. 20(1) 23-41.

Dellaert, B., N. Syam. 2002. Consumer-producer interaction: A strategic analysis of the market for customized products. Working papers, Rev. Marketing Sci. 1(1), http://www. bepress.com/roms/vol1/iss1/paper1.

Desai, P. 2001. Quality segmentation in spatial markets: When does cannibalization affect product line design? Marketing Sci. 20(3) 265-283.

Gabszewicz, J., J. Thisse. 1986. On the nature of competition with differentiated products. Econom. J. 96 160-172.

Lal, R., M. Sarvary. 1999. When and how is the Internet likely to decrease price competition? Marketing Sci. 18 485-503.

Moorthy, K. 1988. Product and price competition in a duopoly. Marketing Sci. 7(2) 141-168.

Moorthy, K. 1991. Erratum to: Product and price competition in a duopoly. Marketing Sci. 10(3) 270.

Morneau, J. 2000. Dynamic pricing: Who really wins? TechWeb (Sept. 29).

Motta, M. 1993. Endogenous quality choice: Price vs. quantity competition. J. Indust. Econom. 41 113-131.

Mussa, M., S. Rosen. 1978. Monopoly and product quality. J. Econom. Theory 18 301-317.

Shaffer, G., Z. Zhang. 2002. Competitive one-one promotions. Management Sci. 48(9) 1143-1160.

Shaked, A., J. Sutton. 1982. Relaxing price competition through product differentiation. Rev. Econom. Stud. 49(1) 3-13.

Smith, G., T. Nagle. 2002. How much are customers willing to pay? Marketing Res. 14(4) 20-25.

Sweeney, R., R. Davis, M. Jeffery. 2002. Teradata Data Mart Consolidation Return on Investment at GST. Northwestern University, Evanston, IL.

TechWise Research, Inc. 1999. Are proprietary RISC servers more expensive than their UNIX alternatives? (June) 1-12.

Thisse, J., X. Vives. 1988. On the strategic choice of spatial price policy. Amer. Econom. Rev. 78(1) 122-137.

Ulph, D., N. Vulkan. 2002. E-commerce, mass customisation and price discrimination. Working paper, Economic and Social Research Council (ESRC) Center, London, UK.

Villas-Boas, Miguel J. 1999. Dynamic competition with customer recognition. RAND J. Econom. 30 604-631.

Wertenbroch, K., B. Skiera. 2002. Measuring consumers' willingness to pay at the point of purchase. J. Marketing Res. 39(2) 228-241.

Zettelmeyer, F. 2000. Expanding to the Internet: Pricing and communication strategies when firms compete on multiple channels. J. Marketing Res. 37(3) 292-308.

Zhang, J. 2003. The hidden dangers and payoffs of targeted pricing. Wharton Knowledge Center (March 26) http://www.upenn.edu/ researchatpenn/article.php?6197.bus. 